\title{
Anscombe on Practical Knowledge AND THE GOOD
}

\author{
JENNIFER A. FREY \\ University of South Carolina
}

\begin{abstract}
This paper addresses how Elizabeth Anscombe understands the link between action theory and ethics, by focusing on her theory of practical knowledge. I argue that, for Anscombe, a capacity for practical knowledge is best understood as a capacity to do things for reasons, where reasons are the ends pursued by the agent as practically intelligible goods; on this view, knowing what one is doing and knowing the intended good of doing it are two different aspects of one and the same practical knowledge. On my reading of Anscombe, the central task of action theory is to elucidate this capacity for practical knowledge, which is exercised anytime one acts in the characteristically human way (intentionally or voluntarily). The proper task of ethics, by contrast, is to elucidate the perfected exercise of this power in the practically wise or virtuous person-i.e., the one who is properly disposed to act for the right reasons and thus lives well.
\end{abstract}

Keywords: Anscombe, practical knowledge, practical reason, intention, guise of the good

\section{Introduction}

Elizabeth Anscombe's Intention, originally published in 1957, is a landmark text in twentieth century action theory. "Modern Moral Philosophy," published one year later, is at least as influential a text in the history of twentieth century ethics. While much has been written about each of these works separately, surprisingly little has been done to address how they are inter-related. The properly philosophical concern raised by both of these texts is how action theory relates to ethics. In "Modern Moral Philosophy," Anscombe suggests "banishing ethics totally from our minds" until we have an "adequate philosophy of psychology" -

Contact: Jennifer Frey <frey.jenn@gmail.com> 
one that explains terms like 'action', 'intention', and 'wanting' (2005b: 188). This suggests that Anscombe thinks action theory is in some sense the proper foundation for ethics, but she is never clear about why or how this is so.

To address the problem, let us consider two well-known and widely discussed theses from Intention: (1) intentional actions are known in a peculiarly immediate and non-evidential way, and (2) intentional actions are pursued "under the guise of the good." ${ }^{1}$ Let us call these familiar claims the knowledge requirement and the goodness requirement on action explanation, respectively. Both of Anscombe's requirements have come under heavy fire; many argue that not only is it possible to perform actions intentionally without knowing that one is or without understanding one's action as good (or both), but also that such failures are altogether common in the course of human life. ${ }^{2}$ Even those who claim to follow the spirit (if not the letter) of Anscombean action theory typically hold to just one of these theses while explicitly rejecting the other. ${ }^{3}$ For all that has been written about these two requirements, few have noticed that for Anscombe they stand or fall together. On her account, knowing what one is doing and knowing the intended good of doing it are two aspects of one and the same practical selfknowledge.

In this essay, I address the exegetical and philosophical questions raised by thinking about Intention in light of Anscombe's call to cease and desist from moral theory until we understand more basic, action-theoretic terms. The argument proceeds as follows. In Section 2, I discuss the central problem of Intentionwhat I call the specification problem - which is to distinguish intentional from unintentional descriptions of action. Anscombe's theory of practical knowledge is a solution to this problem, one that connects intentional descriptions of action with the agent's practical reasons. I argue that intentional descriptions of action are objects of a special kind of practical knowledge, which I describe as an agent's practical self-knowledge of her own rational capacities in exercise.

In Section 3, I argue that the typical or paradigmatic example of an intentional action is an event whose part-whole structure is constituted by the agent's own practical thought and reasoning, such that we ought to understand human action generally as constituted by acts of practical reason and will, rather than as separately identifiable effects that are "caused" by mental states. In Section 4, I argue that the rational order of action discussed in Section 2 is formally dis-

1. This phrase comes from David Velleman (1992).

2. Donnellan (1963) and Davidson (1980b; 1980d) were early detractors of the knowledge requirement, while Stocker (1979) and Watson (1975) were early detractors of the goodness requirement.

3. For example, Setiya (2008), Thompson (2008), and Velleman (1989) accept the knowledge requirement but not the goodness requirement, whereas Davidson accepts the goodness requirement (1980a), he rejects the knowledge requirement (1980d). 
played in the practical syllogism, which is a representation of the action as the conclusion of a valid practical argument, one whose premises show the good of drawing it. On this account, knowledge of the good is internal to knowledge of action because an agent's knowledge of her reasons constitutes her action into a determinate, practically intelligible kind.

Finally, in Section 5, I conclude with some brief reflections about how an understanding of this capacity for practical knowledge can serve as a conceptual bridge from action theory to ethics. According to my interpretation of Anscombe, the proper task of action theory is to elucidate the power to act for reasons - a power of practical knowledge-which is exercised, however imperfectly, anytime one acts in the characteristically human way. The proper task of ethics, by contrast, is to elucidate the perfected exercise of this power in the practically wise person - that is, the one who is properly disposed to make things happen for the right reasons, and therefore to live well.

\section{The Specification Problem and the Standard Account of Practical Knowledge}

Let us begin with a starting point that few will want to deny: For any intentional performance of an action, it is always the case there will be many true descriptions of what the person is doing that are not intentional. For instance, Jones walks into a room and flips a light switch, and thereby: 'moves such-andsuch muscles,' 'raises his arm,' 'illuminates the room,' 'casts a shadow on the wall,' 'produces a clicking noise,' 'wakes up and perturbs the unsuspecting dog,' 'alerts a prowler to the presence of the owner of the house,' and so on, ad infinitum. Let us suppose that all of these descriptions of what Jones does are true; there remains the question of which descriptions are intentional. A theory of action must supply an answer, as both law and morality depend upon there being some principled way to separate what Jones does as a matter of his practical agency and what he merely effects as a result of his exercise of that agency. Let us call this the specification problem. 4

Anscombe's account of the intentionality of action is anchored in our prac-

4. The specification problem is a problem within action theory, concerning the intentionality of action, but its import is clearly not limited to it. For it is clear that in order to evaluate any action as good or bad, we need to be able accurately to describe what kind of action it is. Suppose that I walk into a room and see someone 'plunging a knife into Smith's thigh.' This level of description is not yet specific enough for moral evaluation. Am I witnessing someone who is properly described as 'defending himself from unlawful attack' or am I witnessing someone 'committing murder'? It clearly matters to our moral evaluation of the action which of these two candidate descriptions is properly intentional, as Anscombe's (1981a) arguments against Truman make especially clear. On this point, see Wiseman (2016: 28-31). 
tice of asking for and providing practical reasons that both justify and explain what one does. Intentional actions, she argues, are the ones "to which a certain sense of the question 'Why?' is given application," where the relevant sense of the question is "that in which the answer, if positive, gives a reason for acting" (2000: 9). Furthermore, we grasp this "special sense" by looking at how we actually deploy and answer the question, and it is within this practice that Anscombe finds the ground for her knowledge requirement.

Posing the 'Why?' question can reveal a description is unintentional when the agent refuses to give the question application under it; this suggests that there must be some connection between the self-conscious application of an action concept to what one does and having a reason for doing it. Anscombe understands the connection in terms of knowledge; she finds it obvious that if Jones doesn't know he is 'waking up the dog' by 'flipping the switch' then he cannot be doing so intentionally. This is the pre-theoretical data her theory seeks to explain.

Unintentional descriptions of action are often revealed from a third personal, observational perspective, and often describe aspects of the agent's performance of which he is totally unaware. ${ }^{5}$ If one discovers that he is $\phi$-ing-that is, if he knows it only in a third personal way - then eo ipso, he is not $\phi$-ing intentionally. ${ }^{6}$ Intentional descriptions must be known from the first personal, deliberative perspective, as they pick out action concepts that the agent himself self-consciously applies to his performance.

Another feature internal to this practice is that the intentional descriptions underwriting it are typically "vague and indeterminate" (Anscombe 1981c: 4). For example, suppose that someone asks Jones, mid-stroll,

"Why are you walking up Fifth Avenue?"

and he replies,

"I'm going to the Giant Eagle to buy some milk."

The answer reveals no details about the purchase itself, such as which bottle he will grab, which cash register he will approach, or how many steps he will take. Although there will in fact be determinate and fine-grained answers to all of these questions once his action is complete, they are plainly outside the scope of the question and the responses given.7

5. This is not to say that intentions cannot be observed, as Anscombe (2000: 8) believes they can.

6. Of course, one may discover that she is doing something unintentionally, and then choose to continue doing that thing intentionally. But then she will do it with the requisite practical knowledge.

7. We can cook up circumstances in which these descriptions would matter: our agent is tracking the number of her steps for health, or she's a spy who knows that the third carton to the 
The role of practical salience in specifying intentional descriptions foregrounds the fact that one's answer to the 'Why?' question has to reveal one's knowledge of one's reasons for acting under that description. But what is the character of such knowledge? Anscombe takes a negative approach to this question at first; rather than explain what such knowledge is, she proceeds by saying what it is not. It is not simply non-evidential knowledge of what one does. To show this, Anscombe imagines someone excitedly knocking a cup over, because "I thought I saw a face in the window and it made me jump" (2000: 8). This response, she claims, gives a "mental cause" rather than a reason, but such a response does not imply a lack of non-evidential or first personal knowledge of what one does. ${ }^{8}$

Careful attention to Anscombe's discussion of our non-observational, noninferential, and non-evidential knowledge of the "mental causes" of action ought to cast significant doubt upon the typical approach to understanding Anscombe's knowledge requirement, according to which it is specified by appeal to some list of special features. It is often argued, for instance, that what is distinctive about knowledge in intention is that it must be "non-observational" or "non-inferential." This way of proceeding implies that we should start by taking for granted some common genus of knowledge we antecedently understand, and then distinguish practical knowledge in terms of its distinguishing features. On such a method, we explain the knowledge requirement just in case we explain why any candidate feature applies to it. 9

This method yields unsatisfactory results. It is obvious, for instance, that knowledge of action is not distinctive insofar as it is non-observational. There are arguably many forms of knowledge that don't depend on observation and have nothing to do with action (e.g., knowledge that 9 is the square root of 3 ). Arbitrarily restricting non-observational knowledge to action is no solution, as knowledge of mental causes makes clear. One could easily run the same style of argument against other putative candidates, such as its non-inferential or essentially first personal character.

The problem only becomes more acute once we turn our attention to other features of practical knowledge that Anscombe mentions. In order of appearance, these include:

left of the butter contains a secret message from the Russians. However, this underscores the point about practical salience rather than detracts from it.

8. In Anscombe's discussion of mental causes, it is clear that a mental cause picks out what produced the agent's behavior - that is, what event brought about the effects under those descriptions. A mental cause does not have to be some mental item -it could be a knock at the door.

9. Exemplars of this method include Gibbons (2001; 2010), Hursthouse (2000), Moran (2004) Setiya (2007; 2008; 2017) and Velleman (1989). 
1. When the knowledge fails, the mistake is not one of judgment but performance (2000: 5 ).

2. The contradiction of a statement of this knowledge is not a contrary statement of fact, but the performance of an act that contradicts the intention specified in the statement (2000: 55).

3. The knowledge is only comprehended to the extent that practical reasoning (or the practical syllogism) is (2000: 57).

4. The possession of such knowledge implies some capacity for knowhow or skill (2000: 87-88).

5. The knowledge is "the cause of what it understands" (2000: 87-88). ${ }^{10}$

6. Objects of this knowledge are formally such as to be subject to the question 'Why?' and therefore related to a formally articulate teleological order of means and ends (2000: 88).

Needless to say, the usual approach of specifying some set of privileged features tends to generate theories that cannot even begin to explain these other aspects of Anscombe's account. Perhaps, then, what is missing from our understanding of the knowledge requirement is not some further, hitherto unnoticed property we might add to the established list, but an account of how practical knowledge is a different mode of knowing altogether. This suggestion certainly fits with Anscombe's own diagnosis of the problem she faces in providing an account of the knowledge requirement-viz:

we have an incorrigibly contemplative conception of knowledge. Knowledge must be something that is judged as such by being in accordance with the facts. The facts, reality, are prior and dictate what is to be said, if it is knowledge. And this is the explanation of the utter darkness in which we found ourselves (2000: 57 ).

Anscombe suggests that we will make no progress in understanding the matter so long as we remain beholden to this inherited framework. According to it, knowledge is fundamentally about grasping or taking in some independent reality (the facts); these independent facts are the measure of whether any claim amounts to knowledge, and a mistake consists in a mismatch between these facts and the statement that purports to express a judgment about them.

Practical knowledge cannot be shoehorned into this frame. One way to see this is to consider what counts as its failure. Of practical failure, Anscombe writes that

10. Setiya (2017) denies this condition on practical knowledge is "definitive" but only holds sometimes. Although careful discussion of his arguments is beyond the scope of this paper, it will become clear as my own argument progresses that I disagree with how he understands Anscombe's invocation of the phrase "form of description of events." 
The mistake is not one of judgment but of performance. That is, we do not say: What you said was a mistake, because it was supposed to describe what you did and did not describe it, but: What you did was a mistake, because it was not in accordance with what you said (2000: 57).

A failure of practical knowledge is not a failure to grasp the way things are independently of one's practical perspective-a mistake in what is said-but a failure to make things the way one wants them to be from that perspective. This is a distinctive mode of failing, which the standard approach to practical knowledge cannot explain.

All this is not to deny that part of the story about the knowledge requirement is that the subject's knowledge of action is possessed without observation, inference or evidence, and that we do have first person authority over and privileged access to the intentional descriptions of our actions. Rather, it serves to make especially clear what is often left unexplained or simply taken for granted: that it is the practical character of this knowledge that stands in need of explanation.

A final consideration we need to address is how Anscombe understands the object of practical knowledge - that is, the question of what intentional descriptions are descriptions of. The standard response-the one that Anscombe rejects as a "mad account" - relegates knowledge of intention to something primarily inner: intentions, plans, thoughts, or attempts construed on the model of mental states with certain causal properties. By contrast, Anscombe argues that what is known is the action itself-an observable event unfolding in the world. Anscombe proposes the formula, "I do what happens", on the grounds that "when the description of what happens is the very thing which I should say I was doing, then there is no distinction between my doing and the thing's happening" (2000: 52).

Very few readers of Anscombe wish to embrace this formula, for the following reasons. ${ }^{11}$ As finite and fallible creatures, obviously our knowledge of events is mediated by the senses, and it is simply a fact that we often fail to do what we intend to do. Therefore, we cannot know what we are doing simply by intending to do it. A person can know "what happens" only "by observation to be the result" of what he can know without observation or inference-his intentions, beliefs, pro-attitudes, or other mental states, dispositions, or events (2000: 51). Let us call this common objection the argument from practical fallibility. ${ }^{12}$

I do not think we should be impressed by this argument, as it assumes precisely what Anscombe's theory denies-viz., that there is always a potential

11. Some recent exceptions to this general consensus include Campbell (2018), Haddock (2011), Marcus (2012), Rödl (2007), Small (2012) and Thompson (2011).

12. The argument has been forcefully pressed by Paul (2009). For further discussion, and its parallels to the argument from illusion in the philosophy of perception, see Frey and Frey (2017). 
epistemic gap between two independently specifiable realities: an agent's intention to $\phi$ and her actual performance of $\phi$-ing. A successful epistemology of action, on this picture, would show how this gap can be successfully bridged. Such an account assumes that a failure of practical knowledge consists in some form of mismatch between two independently specifiable items (typically mental states or propositional attitudes on the one side of a causal relation and physical events on the other $).{ }^{13}$

On Anscombe's view, by contrast, an agent's intentions and action are, at least in the paradigmatic or successful case, part of one and the same rational order. That is, an action is not the specifiable effect of some separately identifiable prior cause but an event in progress that is constituted by the agent's own practical thought and will. An intentional action comes into existence as a determinate kind - an act of $\phi$-ing - only through the agent's own self-conscious activity of practical reason and will. It follows that a failure of practical knowledge is not a mismatch between two separate realities - intentions and actions - but a failure of one's self-conscious practically rational activity to be fully realized in some particular set of circumstances. This is failure of a distinctively practical sort: a failure to constitute the facts according to one's intentions, rather than a failure to correctly represent independently specifiable facts.

Thus the argument from practical fallibility is not simply an innocuous appeal to the fact that we are finite and fallible creatures, but a philosophically suspect way to explain this. ${ }^{14}$ The explanation is suspect because it rests upon an assumed framework of thinking about a person's knowledge of her own action that is, to use Anscombe's terminology, contemplative, since its measure is "derived from the object known" (2000: 52). On such a model, "the facts, reality, are prior, and dictate what is to be said, if it is knowledge" (2000: 57).

Unintentional action descriptions are true descriptions of what happens, but they are not objects of practical knowledge. Anscombe allows that there are two ways of knowing an action but only one thing known. Or, to put it another way, she allows that one and the same event can be known under intentional descriptions (i.e., practically and first personally) and in another way under nonintentional descriptions (contemplatively and third personally). The argument from practical infallibility either does not understand this aspect of Anscombe's view or does not take it seriously.

The specification problem gives us reason to take it very seriously, and Anscombe's aversion to the standard causal theory is best explained in light of it. Davidson, the influential architect of the causal theory, takes the question of

13. For further discussion of this tendency in the literature, see Lavin (2013).

14. Fernandez calls the assumptions at work here "Burleyanism, since the Medieval Walter Burley was the first thinker to separate practical judgments from actions in such a way as to understand them as 'distinct existences'"' (2016: 871-873). 
the proper specification of action descriptions for granted, and concerns himself with the question of rationalization, of how an agent's reasons can be said to cause events under such descriptions. ${ }^{15}$ Anscombe, by contrast, thinks that the questions of rationalization and specification are one and the same query. This is why her inquiry is into what could possibly count as an intentional action description in the first place; she is not looking for antecedent causes of an already specified event, but "a form of description of events" to which every intentional description, qua intentional, conforms.

In the next section, I will argue that this "form of description of events" articulates the inner practical nexus of a human act, a teleological structure in which human action concepts are typically deployed in practical thought and pursued and realized through acts of will.

\section{Practical Knowledge and the Unity of Action}

The standard causal account of action marks the crucial distinction between intentional and unintentional descriptions solely in terms of the psychologicalcausal antecedents of the phenomena so described. Such a theory, in addition to ignoring the difficulties of the specification problem, has the ironic distinction of leaving the action itself radically un-theorized, as Harry Frankfurt (1978) has argued. Frankfurt notes that an action takes time to be brought to its completion and this fact demands an active agent that sees the performance through to its specified end; one obvious trouble with the Davidsonian theory is that it can only account for the activity of the agent up to the time the action is 'caused' by his psychological states. Once the action has 'gone off', as it were, the subsequent 'effects' - that is, the actual performance or doing - is simply a matter of nature taking its course, as Davidson himself admits (1980b: 50).

Second, as Frankfurt notes, the causal theory casts the explanandum in too narrow a frame. Other animals are active rather than passive with respect to the ends they pursue - that is, the actions they perform. To see this, consider the difference between a spider that moves its legs naturally as it scuttles across its web towards an insect, with a spider whose legs are moved in precisely the same ways towards precisely the same end, but on account of being manipulated externally. We find in the spider the same contrast between goal directed activity attributable to the whole spider, by contrast to bodily movements that can only be located in some part of the spider's body; so here too we find we can mark a contrast between what happens to the spider's body and the actions we can at-

15. Davidson thinks that reasons allow us to "redescribe" actions, but he doesn't seem to think that reasons initially specify them into kinds. And he famously settles on the idea that rationalization is a species of causal explanation (1980a). 
tribute to the spider itself. Propositional attitudes strike Frankfurt as a poor candidate to delineate the difference in question, since a spider presumably lacks those. Moreover, we rational animals can be entirely passive not only with respect to our own propositional attitudes but also with respect to the movements they sometimes cause without our wanting them to. Finally, we are perfectly capable of behaving as mindlessly as the spider. Most of the things one does from habit, for instance, are not explained by what was going on in one's head prior to the performance. But for all that, habitual actions are typically intentional, rational, and explained by the agents who perform them immediately and without any special difficulty.

Frankfurt's arguments against the standard causal account highlight the need to theorize the action itself, and for Anscombe in particular, this means paying special attention to its internal structure or form, as this is the key to understanding the connection between an agent's reasons and actions, a connection that, by her lights, is neither psychological nor causal but grammatical. ${ }^{16}$ Furthermore, Anscombe notes that the internal teleological structure of action can be applied to the movements of other animals, and she stresses that this internal form is temporally structured. ${ }^{17}$ In this section I will begin to argue that the articulation of this form is central to understanding how the knowledge requirement and the goodness requirement are mutually illuminating. ${ }^{18}$

In $\S \S 23-26$ of Intention, Anscombe draws our attention to the fact that answers to the 'Why?' question typically place what a person is presently doing in a rationalizing relation to other descriptions of what he is doing. ${ }^{19}$ This high226).

16. For a full account of intentionality as a grammatical concept, see Frey and Frey (2017: 219-

17. I take it that she means to indicate that the general schema she has outlined can be analogously applied to animals (and, in a deeper way, small children that are in the process of learning to act for reasons) in roughly the same way Aquinas (ST I-II 6.2) thinks it can be so extended. Within the Aristotelian tradition, analogous concepts share no single definition but manifest an equality of proportions that make the use of the same term no accident. But it would be strange to think that we would understand the concept of intention by focusing on the acts of small children, who are just learning to answer the 'Why?' question in intelligible ways, or animals, who can never answer it (we supply answers for them, based on our knowledge of their life form). In whatever analogous sense we can say that small children and animals have practical knowledge of their actions, this is an extension of the paradigmatic case that interests Anscombe: the case of adults who can deliberate about their reasons and therefore know what they are doing in a deeper and more perfect way. Therefore, we should not make specious arguments from the fact that animals behave intentionally in an analogous sense of the term to the claim that there should be a single definition of intention in common between animals, children, and sane adults. For a more detailed account of an analogical unity of terms, see Frey and Frey (2017: 243-245).

18. For recent work on the role of form in action explanation, see Ford (2015), Rödl (2007), Small (2012), Vogler (2001), and Frey and Frey (2017).

19. Of course, this is not always the case. Anscombe admits that sometimes we act for no reason at all or for no further reasons. Anscombe calls such actions a "curious intermediary case: the question 'Why?' has and yet has not application" and she further notes that an action of this 
lights a fact the causal theory obscures, viz., that actions unfold over time, such that the present activity typically contains within it some reference to a not yet realized future. ${ }^{20}$

For instance, at present I am moving my fingers because I am typing out these letters on my keyboard; further, I am typing out these letters because I am writing a sentence; I am writing a sentence because I am making an a point about action; and I am making this point because I am writing an essay on practical knowledge; and so on. In this structure of explanation, the not yet realized future informs the present and makes it intelligible-viz., the movement of my fingers makes practical sense in light of its relation to the completed essay that does not yet exist. Michael Thompson (2008) has called this form of explanation "naïve rationalization," which is the explanation of action on the grounds that it is a proper part or more determinate specification of another action. Such rationalizations characteristically fit together action descriptions into a determinate teleological nexus: A because (in order to) B, B because (in order to) C, C because (in order to) D. ${ }^{21}$

That actions typically have such a part-whole or means-end form is the upshot of Anscombe's famous example of the man pumping water into a cistern. He is described as:

7. moving his arm up and down (A-ing)

8. operating a pump connected to a cistern (B-ing)

sort is "voluntary rather than intentional" (2000:26). To explain this distinction in full detail is outside the scope of this paper; but it is clear that for the purposes of understanding intentional action, such cases are of limited interest and secondary, only to be grasped in light of the primary or paradigmatic case. Anscombe is clear that if we only did things for no particular reason, or had only present intentions, or only acted on what she calls "backward looking motives" then "the notion of intentional action itself would be a very thin one; it is not clear why it should be marked off as a special class" (2000: 32 ). Similarly, it is a mistake to formulate her thesis as taking the form of a Fregean universal generalization, easily vitiated by a single counterexample. First, because most examples pick out merely voluntary rather than intentional actions, and second, because this depends on a non-Aristotelian notion of essence popularized by Fine (1994) which there is no evidence Anscombe accepts, and that certainly does not fit her characterization of her own project as looking at the paradigmatic or typical cases (2000: 30-33). For a careful discussion of the differences of logical form in Fregean and Aristotelian generalizations see Thompson (2008: 69-73).

20. Some recent work on the temporality of actions include Frost (2014), Lavin (2013), Rödl (2007; 2012) Thompson (2008), and Small (2012).

21. Thompson opposes his "naïve rationalizations," ('I am doing A because I am doing B') which are common in human language to the more familiar "sophisticated rationalizations" ('I am doing A because I want to do $\mathrm{B}^{\prime}$ ) of the philosophical literature; the latter, Thompson thinks, depend upon the former. The theoretical preference for sophistication over naivete, Thompson argues, papers over the fact that what the causal theory gives us is not a theory of action - a certain kind of event in the world, logically or grammatically different from other kinds of event-but a theory of psychological states that cause actions as their effects. The effects are taken for granted, the causes investigated. Thompson suggests, rightly I think, that this puts the cart before the horse. 
9. replenishing the house water supply (C-ing)

10. poisoning the Nazis inside the house (D-ing)

These actions are fitted into the structure of naïve rationalizations as Thompson defines them; they form a series of nested practical rationalizations such that the 'Why?' question applies to each of them as we move up the series.

The example illustrates the part-whole structure of action, which is defined by the end that gives it its formal unity (e.g., poisoning Nazis). Whatever one does for the sake of it-moving an arm, operating a pump, and moving water through a pipe-will be a constitutive part of this act of poisoning. By a constitutive part, I mean a part whose identity qua part depends on its role in realizing the whole, such that without reference to the whole there can be no identification of a part. Because moving one's arm up and down is a constitutive part of a poisoning, we can say that in moving an arm up and down, here and now, a poisoning is in the process of being realized. ${ }^{22}$

Of course, all sorts of true descriptions of what the agent does will not count as parts of his action in this sense, precisely because they are not constitutive parts of a poisoning. For example, Anscombe remarks that in pumping the water:

Certain muscles, with Latin names which doctors know, are contracting and relaxing. Certain substances are getting generated in some nerve fibres-substances whose generation in the course of voluntary movement interests physiologists. The moving arm is casting a shadow on a rockery where at one place and from one position it produces a curious effect as if a face were looking out of the rockery. Further, the pump makes a series of clicking noises, which are in fact beating out a noticeable rhythm (2000: 37).

This raises the question, why isn't 'making a series of clicking noises' or 'contracting such and such muscles' an intentional description of what this man does?

We begin to see our answer when we notice that the series of 'Why?' questions from $\mathrm{A}-\mathrm{D}$ is the mirror image of a series of 'How?' questions from $\mathrm{D}-\mathrm{A}$ :

"How are you poisoning the Nazis?"

"By replenishing the house supply with poisoned water."

"How are you replenishing the house supply?"

"By pumping water from the cistern."

22. Of course, our ability to say this does not depend on facts about whether the poisoning is being carried out successfully. Suppose the Gestapo shows up and attempts to arrest the pumper. It will still be true to say that the ground of his arrest is the fact that he is presently engaged in an act of poisoning, even if all he managed to do was begin to move his arm. 
And so on. Unintentional descriptions do not correspond to the 'Why?' or 'How?' questions that relate to the agent's action qua intentional; they are not descriptions that are practically salient from the first personal, practical perspective, because they do not relate the present to a specified future in the sense of its being a non-accidental progression towards it.

Note that the ability to pose the 'How?' question presupposes an answer to the 'Why?' question; for we cannot ask how someone is realizing his end unless we know (or think we know) what the end is. The means are always only means in relation to some specified end. The agent's ability to answer both questions rests upon a logically prior ability to answer a 'What?' question: 'What is it you are up to?

Our questions reveal that an agent must know what he is ultimately doingthat is, the act type he is in the process of realizing - in order to know why what he's presently doing is a constitutive part of its achievement. The end, or that for the sake of which, specifies the agent's action into a kind and determines what counts as a legitimate means in relation to it; therefore practical knowledge of the end is prior to practical knowledge of the means. ${ }^{23}$ Knowledge of the rational connections among the elements of an action are prior to the action's realization, for the agent must know what he is doing generally in order to see her present activity through to its completion; without such knowledge, he can have no measure against which to assess whether and how is he is making progress, here and now. An agent must, as Frankfurt noted, actively see the performance through to its intended term of completion.

This explanatory role for end as the terminus ad quem of a movement or process is not unique to the explanation of human action; it is common to the explanation of the movements of living things more generally and is therefore a fundamental aspect of our representation of a thing as alive. ${ }^{24}$

For example, although we can characterize the mechanics of mitosis in a general way, Thompson (2008: 55) notices that when this material process takes place in different living things it is a different kind of process altogether: in a human it is growth or self-maintenance, whereas in an amoeba it is reproduction. If we stay at the level of description of what we can observe presently changing in the matter and do not take into account that for the sake of which these changes are occurring, then we could not know what kind of living process is underway; for what it means for these chromosomes to be splitting up in such-and-such ways, here and now, in this kind of living thing, depends upon the end for the sake of which it occurs, the terminus ad quem towards which the present movement

23. This is one way to put the Aristotelian point that the formal cause and the final cause, though distinct as forms of explanation, pick out one and the same reality (Phys II.7, 198a22-28).

24. Michael Thompson discusses the role that the life form plays in the explanation of the movements of living things (2008: 25-32, 53-62). 
is non-accidentally progressing. The intelligibility of the parts or phases of the process is provided by the end, which functions as an internal principle of movement and rest. The principle of explanation is internal because it is implicitly contained in any description of the movement of the living thing as a movement within a specific vital process. Of such vital descriptions, we might say, the general (the life-form or end) is always present in the particular movement, which makes it a movement of that specific kind.

In a formally similar way, in order to know what kind of intentional action is happening, here and now, one must have knowledge of that for the sake of which any part or phase of it comes to be, the terminus ad quem. In both cases, the end determines the process at the appropriate level of description and provides it with a measure of success or failure. The end functions as an internal norm or standard-a measure both of what the process is and thereby what constitutes success or failure in attaining it. ${ }^{25}$ Here too the general intended end is present in the particular movement, which makes it a movement of that specific kind.

Insofar as the end serves as a terminus ad quem that both defines and measures the present action, we can follow Christine Korsgaard in thinking of the end as a kind of constitutive principle or standard. A constitutive principle, according to Korsgaard, functions in the way that form does in Aristotle's philosophy of nature; it "unifies what would otherwise be a mere heap of matter into a particular object of a particular kind" (2009: 28). And this is exactly how practical knowledge of the intended end functions in action explanation, as our investigation into the A-D order of action shows - that is, to know the end of one's action is to know what one is presently doing, which could not be known independently. ${ }^{26}$ This is because the parts of an action are more than just functional elements of a greater whole; in fact, they can only be identified as parts through practical knowledge of the intended end.

The notion of a constitutive principle, however, is not sufficient to describe practical knowledge of actions because it does not yet distinguish human actions. In the case of a merely vital process one must have third personal or speculative knowledge of the end, but the reality of the end does not depend upon such knowledge. Mitosis is reproduction in an amoeba regardless of whether anyone comes along to take note of this fact. The opposite is the case in human

25. This is the way that form functions as a principle of explanation in Aristotle (Phys. II.2, 194a27-32; Phys. II.7, 198b2-3; Phys. II.8 199a3o-34; Metaphy V.16, 1021b22-30; Metaphy. IX.8, 1050a6-10; and EN I.7, 1097b22-29ff.).

26. Some have argued that practical knowledge is always and only of the present progressive formulations of action, such as Rödl (2007) and Thompson (2011C). Although the arguments to this effect are off stage for now, with Haase (2018) I deny this. I agree with Haase that what is important about practical knowledge is that its ground is in the agent's practical reason, and this will make it possible to extend practical knowledge beyond the present progressive to include what one has done and what one will do. 
action. Here an agent's knowledge of her end is what makes it the case that her action is properly described in terms of it.

This suggests that the kind of constitutive principle at stake in the two different kinds of process, while analogous, are formally distinct. The former describes a way of being directed to an end that is independent of any knowledge-it picks out a natural tendency - while the latter describes a way of being directed to an end that essentially depends upon self-conscious knowledge of being so directed, it picks out a practical tendency. In the latter case the agent knowingly places herself under the standard internal to the action, and for reasons that are in principle intelligible to others. Thus, she not only knows what will happen next, she knows this because she is the rational source of the principle that determines what comes next. A person knows what she is doing because in order to act intentionally she must constitute what she does through her own practical reason and will: she must decide what to do and how to do it and realize this intentional order in her action. Therefore, we can say that intentional action is a kind of self-constitution: in acting for a reason, a person knowingly constitutes herself and her movements through reason and will.

To return to this specification problem, we can now say that intentional descriptions are typically such as to be objects of such practical knowledge, because to act is to make what one effects in the world to be "formally characterized [sic] as subject to our question 'Why?' whose application displays the A-D order which we have discovered" (2000: 88). To have practical knowledge of action is to have knowledge of what one does in accordance with this general "form of description of events": it is to know what one is doing in light of that for the sake of which one is doing it. ${ }^{27}$

Thus far, we have seen that intentional descriptions must be known from a first personal, deliberative perspective, and that first personal, practical knowledge of the end both specifies an action and serves as an internal standard of goodness or badness for any part or phase of it in progress. This is already to have established that practical knowledge of the end is practical knowledge of the intended good, insofar as that for the sake of which serves as a constitutive standard of the movement's success or failure. The account is incomplete and the specification problem still unsolved, however, until we understand how the knowledge of the intended end is related to an agent's practical reason. In the next section, I will argue that we should understand the practical syllogism as a formal representation of the practically rational unity of an action. The syl-

27. Not all actions display an A-D order. As Anscombe is at pains to insist, some actions are done for no reason (merely voluntary actions), and others have no larger aim, but these are conceptually secondary cases, since there would be no "special sense of the question 'Why?' and no distinct concept of intentional action" if these were the only cases available to us (2000: 32). She concludes that further intentions and purposes are essential to the concept of intentional action. 
logism makes explicit the practically rational character of intentional action: it represents the action in the form of a practical argument that shows how the performance of the action preserves the practical good articulated in its premises.

\section{Practical Reasoning and the Good}

In Section 2 I identified six features of Anscombe's account of practical knowledge and suggested that any proper interpretation of it must show how all six features are essentially inter-related. So far the argument has addressed features (5) and (6): I have argued that the A-D order of action is a means-end order, which the 'Why?' question (with its corresponding 'How?' question) makes explicit. I have further argued that objects of practical knowledge (intentional action descriptions) are formally such as to be subject to this question and thus formally related to this order. But these connections are neither pellucid nor convincing except in light of features (3) and (4), which concern practical reason.

Anscombe remarks that practical knowledge cannot be understood apart from practical reasoning, because the A-D order of action is determined through the exercise of our capacity to reason or to deliberate about what to do. So we must understand how she thinks about practical reason in order to grasp her account of practical knowledge. Anscombe agrees with the Aristotelian tradition that what makes practical reason distinctive is its end or aim: to realize the good rather than know the truth. This is why Anscombe says that it typically has "the form of a calculation what to do" (2000: 60) rather than what to believe, and that its conclusion is typically the performance of an action.

The division in modes of reasoning grounds a further division in kinds of inference. In her article, "Practical Inference", Anscombe notes that the concept of inference is related to some account of its validity, and moreover that "the validity of an inference is supposed to be a certain formal character," the appreciation of which is "connected with the evaluation of grounds qua grounds" (2005c: 113). If there is a distinctive kind of practical reasoning and inference, then its validity will have a different kind of ground from the validity of theoretical inference; this difference is ultimately grounded in the different starting points and aims of the two types of reasoning. In practical reasoning, Anscombe writes,

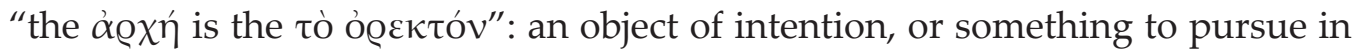
one's action. ${ }^{28}$ To desire an object in this specific sense-a rational form of desire, or will-is to tend towards it in some respect, or to want to possess it for oneself.

28. To say that what gets represented in the first premise is an object of intention is not to say that it is an intention, as Müller (1979) and Wiseman (2016) have both argued. A better way to put the point is to say that it is the intentional description that does the work of specifying the action into its kind, by picking out its terminus ad quem. 
For this reason, the goodness is primarily ascribed not to the wanting, but to the object that is wanted -it is wanted under some description the agent can rationally (i.e., inferentially) connect with her general conception of how to live, of what needs pursuing or avoiding in her life in a general way. ${ }^{29}$

Practical deliberation is a search from some general object of intention to the particular act that will realize it in some specific set of circumstances. Because of its aim, practical inference functions differently from its theoretical counterpart. Anscombe writes:

For in the sphere of practical reasoning, goodness of the end has the same role as truth of the premises has in theoretical reasoning. This is the great Aristotelian parallel: if it is right, then the goodness of the end and of the action is as much of an extra, as external to the validity of the reasoning, as truth of the premises and of the conclusion is an extra, is external to the validity of theoretical reasoning. As external, but not more external. We know that the externality is not total. For truth is the object of belief, and truth-preservingness an essential associate of validity in theoretical reasoning. The parallel will hold for practical reasoning (2005: 146, emphasis added).

The "great Aristotelian parallel" between practical and theoretical reasoning is grounded in the difference between cognition and appetite, and in particular, the difference between the respective intentionality of their objects. This corresponds, non-accidentally, to the different starting and end points of the two types of reasoning.

Anscombe's suggestion is that good is the formal intentional object of a power of will, just as truth is the formal intentional object of a power of judgment. So, just as one believes $p$ insofar as one takes $p$ to be in some sense true, one wants to $\phi$ insofar as one takes $\phi$-ing to be in some sense good - to be pursued. The relation between a subject wanting to $\phi$ under some descriptions and $\phi$-ing seeming good or desirable to pursue under those descriptions grounds the claim that goodness preservation is the "essential associate" of validity in practical reasoning, just as the conceptual relation between a subject believing that $p$ and taking $p$ to be in some sense true grounds the claim that truth preservation is the "essential associate" of validity in theoretical reasoning.

For example, the first premise of a theoretical argument is a representation of the content of some possible belief $p$, which, in conjunction with suitable prem-

29. An agent can simply want something, a kind of brute inclination. But this sort of wanting is outside of Anscombe's investigation and would not count as an object of intention. For further arguments that Anscombe is after a restricted notion of wanting to which the 'Why?' question applies, see Wiseman (2016: 145-147). 
ises yields a proposition as a conclusion that preserves the truth of the premises. Theoretical arguments represent potential moves from beliefs to beliefs and preserve truth, whereas the first premise of a practical argument is a representation of a possible object of intention, to $\phi$, which, in conjunction with premises stipulating the suitable means to attain it in some concrete circumstances, yields an action that preserves the good of the premises. For instance, if what I want is to eat dinner because I'm hungry, I realize that good only after I have eaten something specific and am full. Practical arguments represent potential moves from general intentions to particular actions that realize them materially; therefore, they are goodness preserving.

Anscombe argues us that the syllogism "describes an order which is there whenever actions are done with intentions; the same order I arrived at in discussing what 'the intentional action' was" (2000: 80). This order is the practical means-end order of action discussed in the previous section. If the series of 'Why?' questions is meant to help elicit this order, thereby making explicit the agent's practical reasons or grounds, the syllogism is meant to formalize it, thereby making it into a proper subject of rational analysis. The syllogism displays the order of action in the form of a practical argument, the conclusion of which is the realization of the good specified in the premises. As the conclusion of a practical argument, the action is intelligible in light of its premises, which "shew what good, what use, the action is" (2005c: 114). Such an order, we have seen, can only come to be in the agent's practical self-knowledge that it is so coming to be; it is self-knowledge of how a particular action, even in its incipient phases, is a partial realization of the intended good.

I have been arguing that what is represented in the first premise of the syllogism is the object of intention, which is a specifically rational form of desire. Many of the sections dedicated to practical reasoning in Intention are taken up with characterizing this restricted sense of wanting, but for our purposes two hallmarks of it are especially important: (1) its role as the starting point of practical reasoning and (2) its intentionality, which is characterized by its relation to the question 'Why?'.

With respect to ( 1 ), Anscombe follows Aristotle in taking the starting point or principle ( $\dot{\varrho} \chi \eta \dot{n})$ of any practical reasoning to be some good that the agent wants to pursue. Without this, there is nothing for practical reason to operate on - no characteristic work for it to do. What can be brought into a first premise of a syllogism, or be an object of intention, is no mere idle wish, hope, or prick of desire, but something the agent is "trying to get."

Now, in order for someone to tend to be "trying to get" some object of desire, one must possess the skills necessary to attain it. Therefore, it seems to be a general constraint on an object of intention (what falls within the scope of a first premise) that one possesses a certain kind of "know-how" with respect to it. It 
seems impossible for someone to intend to slam dunk, for instance, if one has no demonstrated ability to do this successfully. ${ }^{30}$

With respect to (2), Anscombe argues that an object of intention is an object of desire that typically goes beyond reference to something as merely pleasant or habitually pursued (2000: 76). ${ }^{31}$ This is the reason that Aristotle puts 'should' in the first premise of his account of the syllogism, and we can see that this is the sort of should that relates to her special sense of the question 'Why?'. She reminds us that 'should' "is a rather light word with unlimited contexts of application," some of which are:

That athletes should keep in training, pregnant women watch their weight, film stars their publicity, that one should brush one's teeth, that one should (not) be fastidious about one's pleasures, that one should (not) tell 'necessary' lies, that chairmen in discussions should tactfully suppress irrelevancies, that someone learning arithmetic should practice a certain neatness, that machinery needs lubrication (2000: 64).

Although 'should' is "light" it is normative, and since many philosophers have driven a wedge between so-called motivating and normative reasons, ${ }^{32}$ we need to explain its normative character.

Anscombe writes that

the question, 'What do you want?' in the context of action explanation is the question 'With a view to what are you doing $\mathrm{X}, \mathrm{Y}$, and Z?', which are what he is doing. That is to say, it is a form of our question 'Why?' but with a slightly altered appearance (2000: 63).

Moreover, she thinks that we can typically press this form of the 'Why?' question with regard to the intended end that appears in the first premise of a practical syllogism, answers to which show how the pursuit of that end is rationally desirable and salient from the agent's first person practical perspective. The response to the question will be given under descriptions that shows how the agent conceives of the end as "in some sense good," where 'good' can be formally characterized as 'useful' (instrumentally good for the realization of some further end), 'suitable' (good in itself, given the agent's vision of the good human life in gen-

30. One can intend to learn or to try to slam dunk, but that is a different intention. On the importance of skill in practical knowledge, see Small (2012: 204-207).

31. A compulsive disposition to wash one's hands or a thoughtless disposition to twirl one's hair would not count.

32. The locus classicus for this distinction is Smith (1987). 
eral), or 'pleasant' (as something the agent is aware of enjoying). ${ }^{33}$ Without this relation to the good and the question 'Why?', Anscombe thinks that the idea of a specifically rational form of wanting fails to have any special sense, and action theory fails to have a special topic in its own right. 34

If the intentionality of rational desire depends on its being determined suitable, useful, or pleasant, this intelligibility depends on a look to the wider context of one's life in progress. An object of will is wanted under descriptions that are (at least potentially) inferentially connected to the wider context of a human life, since it is from the ends or goods that constitute one's life that one determines what one has practical reason to pursue, here and now. One intends (rationally desires) the particular in light of the general (2000: 72-76).

For example, suppose that one's intended end is to roast a pig for dinner. One can always ask why this is the intended end, and the rationale given will typically hang on its inferential connections to the agent's more general ends: she thinks, for instance, it is permissible to eat animals; she has been wanting to make a good impression on her colleagues; she enjoys roasted pig and believes that she can carry it off, etc. Notice that the determination of the means will be essentially practical in the same way, since there are any number of ways to roast a pig, one of which is set the house on fire. But unless she's been yearning to destroy her property and collect on the insurance, this is not an attractive option, and its unattractive character is made intelligible by the general ends she is after in her life: the standing need for shelter, financial stability, home ownership, a desire to evince collegiality and hospitality, etc. (Anscombe 2005c: 145).

The point of the example is to illustrate that the means are also identified and chosen in light of one's general ends as applied to the particular circumstances. 35 The rational intelligibility of the practical determination of means or ends depends upon its inferential connection to the wider context of a life in progress, which has been and will continue to be shaped by one's general sense of how to live. ${ }^{36}$ To put the same point another way, ends get their practical intelligibility as ends by implicit reference to other ends, including the general ends of human life as understood by the subject of action. Therefore, the full intelligibility of any practical syllogism always makes reference to other syllogisms, just as the

33. For an excellent discussion of the threefold characterization of the good, see Vogler (2002).

34. For further discussion of this point in relation to the concept of practical truth and the syllogism, see Torralba (2016).

35. For further arguments for the practical nature of the second premise, see Ford (2016) and Müller (1979).

36. This does not mean that one explicitly thinks about one's life before acting; these connections are very often implicit, and the 'Why?' question serves to make them explicit. Anscombe's claims about practical reason are not best understood psychologically, but logically. For more arguments to this effect, see Wiseman (2016) and Frey and Frey (2017). 
intelligibility of one action is usually understood by way of its relation to another action. ${ }^{37}$

In order to prevent misunderstanding, it is important to stress that we should not understand the syllogism as making a claim about an agent's psychology at any particular moment. Anscombe does not believe that we have to think or deliberate explicitly about how to act prior to acting or that the general conception of how to live under which we operate has to be made explicit in one's practical thought. For example, take the banal case of shooing away a spider because one finds it creepy. Being habitually disposed to fear spiders can serve as a reason for action insofar as it can be grasped as the intelligible ground of the sort of action so described. Shooing away a spider is practically intelligible; plenty of people find spiders scary and avoid them.

The conclusion of the practical syllogism is the realization of the order of intention specified in the premises; it represents "an action whose point is shewn by the premises, which are now, so to speak, on active service" (2000: 60). If we think of the premises as articulating an order of intention (A-D), we should think of the conclusion as an action that is defined by an order of execution (D-A). It is the very same rational order, with the difference that, as the scholastic dictum says, "what is first in the order of intention is last in the order of execution." 38 Both orders - intention (A-D) and execution (D-A) - take the form of "Aristotelian necessities": they represent their elements as good insofar as they are necessary to the attainment of one's ends. 39

We can now connect this practical self-knowledge of action with Anscombe's thoughts about "the great Aristotelian parallel" in practical reasoning. The action or performance (the conclusion) is a preservation of the goodness of an end sought (first premise) through some particular means (second premise). An action qua conclusion is the actualization of the good that only potentially exists in the premises. A practical syllogism will be valid if what is specified in the premises meets some determinate measure of correct calculation such that the conclusion can be drawn-that is, if some apparently potential good becomes actual through the means specified. A practical inference is one that is measured by this specifically practical notion of validity. Attention to Anscombe's analysis of the syllogism, not as an analysis of a psychological process that occurs prior to acting or more generally, but as a form of reasoning internal to the action itself, further deepens our understanding of practical self-knowledge of action as practical self-knowledge of the intended good.

37. For a conception of the practical syllogism in terms of naïve rationalizations, see Wiland (2013).

38. One finds essentially the same thought in Aristotle. See De Anima, III 433a: "that which is last in the process of [practical] thinking is the beginning of the action."

39. On the concept of "Aristotelian Necessity" see Anscombe (1981b: 18). 
Of course, "the intended good" in this formulation is formal rather than material, the sense of good defined by a formal account of practical validity, which again, pays attention to "the logical features of practical reasoning" rather than materially specific ethical evaluation (2000: 72). While killing Jewish children seems good to Anscombe's Nazi, and this is what he intends to do by setting up a mortar, he has not thereby determined the correct or true good to pursue. Anscombe's point in these sections is to demonstrate that insofar as he has exercised his practically rational capacities at all he has practical knowledge of his intended good or knowledge of his practical reasons for intending this end (that this sort of action "befits a Nazi", a judgment that presupposes some conception of the good life for a Nazi). Whether his reasons are truly good is not a question Anscombe addresses, as this would depend on whether his general conception of how to live is a true one. Moreover, Anscombe is clear that the syllogism "as such is not an ethical topic" and nothing I've argued in this section suggests otherwise (2000: 78).

To sum up the argument so far: The central aim of Intention is to give an account of action that addresses what I have called the specification problem. Anscombe's account does this by providing a theory of the agent's practical mode of knowing the intentional descriptions of her actions; one must have this knowledge because acting is the activity of realizing a self-determined order of practical reasons. On Anscombe's account, to know the end or intention in acting just is to know the good of pursuing it in the formal sense outlined by her account of the practical syllogism, which gives a determinate sense to claims of practical intelligibility connected to a notion of practical inference and validity. Intentional descriptions of action are objects of practical self-knowledge insofar as they are determined by the agent's practical reason and will; they are therefore potential candidates to appear in a practical syllogism, whereas unintentional descriptions are not.

We now need to turn to the remaining items on our original list, which pertain to practical failure and contradiction. Although a full account of practical failure is outside the scope of this essay, it is important to give a brief sketch of how it can be accommodated. Practical failure may occur in at least two ways: (1) the agent herself fails to be doing what she says she is doing and there is no chance of positive correction, and (2) the agent is prevented or interrupted from doing what she intends because someone interferes. Both depend upon an agent's possession of practical knowledge as self-knowledge of the intended good.

We have already noted that a failure of knowledge in intention is not a failure to grasp the way things are independently of one's practical perspective, but a failure to make things the way one has decided they ought to be. Therefore, it cannot be understood as a mismatch between two independently specifiable 
realities - intention and action - but rather as a failure of self-constitution: a failure to realize the rationally determined order of intention in one's action. The first sort of failure is then not a mistake in judgment or reason, but a "mistake in performance" or execution.

We may, adopting Anscombe's language in a later essay on practical truth, say that it is a failure to "make true" the intentional descriptions of what one is doing (1981d: 153). Remember that unintentional descriptions of what happens when an action acts are also true, but they are not practically true because they do not depend on the sort of practical knowledge of the intentional order of action outlined above. When Anscombe speaks of practical truth, she means "the truth one produces in acting according to choice and decision" (2005d: 155); this is the truth one produces through the exercise of one's practical reasoning and will in acting intentionally, the truth that pertains to intentional descriptions of action. Anscombe further characterizes it as "truth in agreement with desire", where desire is clearly the agent's desire for the intended good. Such practical truth is by no means guaranteed. But if a person fails to do what she intends - that is, fails to make intentional descriptions of her action true-she fails fully to actualize her powers of practical reason and will. In such cases, the descriptions she "makes true" will not be in agreement with her deliberative will, and her claims to have practical knowledge of what she does will fall to the ground..$^{\circ}$

Another potential kind of practical failure depends upon a "practical contradiction"; this is when one fails to do what one intends because someone else acts intentionally so as to interfere and oppose. For example, a possible practical contradiction of 'I'm replenishing the house water-supply', Anscome argues, is "'Oh, no, you aren' $t$ ' said by someone who thereupon sets out e.g. to make a hole in the pipe with a pick-axe" (2000: 55). The idea of this sort of failure depends upon someone having a deliberative will to frustrate, impede, or interrupt the realization of someone else's intentions. What is important about this sort of failure for our purposes is that it is not intelligible without a grasp of the formal sense of good made explicit by the practical syllogism. To oppose and contradict the will of another is to see that their intentions contradict one's own-that their success is one's own failure.

\section{Conclusion: Action Theory and Ethics}

Having laid out Anscombe's theory of intentional descriptions of actions as objects of practical self-knowledge, we can now return to the initial question of how action theory and ethics are related. In the previous section, I argued

40. For a fuller discussion of this kind of practical failure, see Frey and Frey (2017). 
that the conclusion of the practical syllogism is a realization of the intentional order of reasons, which itself defines a formal sense of the good connected to a concept of practical validity. I noted that Anscombe understands this realization or execution as a kind of "making true" of the intentional order - more specifically, the making true of the intentional descriptions of what one does as descriptions of what happens. The practical character of this truth, I've argued, must be understood in terms of its relation to a notion of practical validity. For it is by "drawing the conclusion" or acting that one preserves the goodness of the end intended specified in the first premise, through the means specified practically specified in the second premise. In the case of the valid practical syllogisms that Anscombe considers in Intention, what is made true is that "what happens" comes under the intentional descriptions specified in the premises. This is "the truth one produces in acting" through the exercise of practical reason and will (2005d: 55).

But just as validity is not the full measure of an argument-it should also be sound - so too truth in agreement with desire is not the full measure of practical truth; the full measure would be truth in agreement with right desire or practical truth sans phrase. ${ }^{4^{1}}$ Such practical truth comes by way of "making true" intentional descriptions that are not merely a correct means to an end that is only apparently good from the agent's practically deliberative perspective, but truly good. In order to make sense of practical soundness and practical truth, however, we need to have available some final or ultimate end against which to measure any particular action. That we need such an end for ethics is implied by Anscombe's analysis of the first premise of a practical syllogism as susceptible to the 'Why?' question in roughly the same way that an intentional action is.

Let us recall that Anscombe understands practical reasons in terms of ends, such that to say that ' $p$ is a reason for action' means that $p$ either mentions some end intended or states some action that promotes some end intended (2005c: 147). To say that a proposition that contains a practical reason is true, then, is to say one of two things for Anscombe: either that we can show how it serves another end the agent intends or that it is good itself. But what is the measure of correct calculation in the first instance or true insight in the second? How can we rationally criticize someone for pursuing some end "where and when it is inappropriate for him to do so, or by means inimical to other ends which he ought to have?" (2005c: 147). Anscombe's response to this question is clear: only if we can make recourse to some "last end which governs all" can the case be made that such reasons are "valid in the strict and narrow sense in which in theoretical contexts validity contrasts with truth." In that case, the deliberation and the reasons will be bad insofar as they did not realize the final end. For

41. See also Aristotle, EN VI.2, 1139a21-30 
although it is true that an action is good if it is in no respect bad, one obvious way for an action to be bad is to show that it is "inimical to the last architectonic end" (2005c: 147).

Anscombe sidesteps the question of the existence of such an end in Intention..$^{2}$ Anscombe does not take herself to be giving a theory of practical reason or a theory of acting well-a task she thinks belongs to ethical theory proper. What Anscombe is after in Intention is an account of the intentionality of action, one that makes it clear that actions are understood in an intensional context and that intentional descriptions of action are objects of a special mode of practical knowledge because actions are constituted by the agent's own self-conscious exercise of her capacities for practical reason and will. Anscombe wants to show how we exercise a certain rational authority over our actions and therefore bear a certain responsibility for them. She sets about showing this by making explicit the practically rational form internal to intentional actions, a form that can be formalized in the practical syllogism.

So while Anscombe avoids the question of what constitutes right practical reasoning in Intention, her analysis of the first premise of the syllogism is the space in her theory where recourse to such an end looks necessary from an ethical point of view - that is, a point of view that will not be satisfied with an account of how actions are constituted by an agent's reasons but that concerns itself with the question of whether those reasons were the correct ones in the particular circumstances. On Anscombe's analysis of the syllogism, for something to show up as a first premise (to be an intended good), it must be shown to be inferentially related to the agent's other intended ends, appear intrinsically good to her, or appear pleasant. In the previous section, I argued that an agent needs to have some general conception of how to live-some general conception of what is useful, fitting, or pleasant within her own life on the whole-in order for her to intend to pursue some end in a way that is rationally intelligible at all. I would now like to suggest that we can think of this general conception of how to live as a formal conception of 'living well', which structures the agent's practical deliberation in such a way that only appeal to it can make sense of what appears desirable to the agent to pursue in particular circumstances. ${ }^{43}$ And if that is

42. Although she thinks some of the old arguments for such an end are fallacious, she certainly never rules out the possibility of such an end governing right practical reasoning. Her task, she reminds us, is not to show that all chains must stop somewhere, but that "some chain must at any rate begin" (2000: 34$)$.

43. Again, this is a claim about the structure of practical deliberation or practical intelligibility rather than a psychological claim. Anscombe manifestly does not think that everyone explicitly deliberates before action or makes these connections explicit in their practical thought. Again, the truth of the claim hangs on the practical intelligibility of what can be a premise of practical reasoning. Given how steeped she was in his thought, Anscombe may be drawing on Aquinas (ST I-II 5.8) as a resource here, who also distinguishes between a formal and a material sense of living well. 
correct then the normative character of the first premise depends upon a formal notion of a general ultimate end.

But there is another space in Anscombe's view where talk of living well makes sense, and that is her discussion of intentional action descriptions whose sense depends upon an antecedent possession of the form of description of events she has identified (2000: 84-86). Anscombe notes that all of the descriptions on her list "go beyond physics" and that one might call them "vital descriptions" (2000: 86) because we can see such descriptions at work in the life of animals.

We certainly ascribe intention to animals ... we describe what further they are doing in doing something (the latter description being more immediate, nearer to the merely physical): the cat is stalking a bird in crouching and slinking along with its eye fixed on the bird and its whiskers twitching. ... The two features, knowledge and enlarged description, are quite characteristic of description of intention in acting. . . We do this though the cat can utter no thoughts, and cannot give expression to any knowledge of its own action, or to any intentions either (2000: 87).

Anscombe associates intentional descriptions with "vital descriptions" because she thinks that it is characteristic of vital descriptions generally that we must look to "enlarged descriptions" of what the agent is presently doing in order for them to be intelligible. As argued in Section 2, this look to the wider context is characteristic of the movements of living things more generally, such that our understanding of the more immediate descriptions of an action depend upon our seeing how they are related to a wider context or enlarged descriptions of it. The recognition of intentional descriptions as "vital descriptions" opens up space for us to talk seriously about the possibility that the most general intentional action description is that of 'living well' and this description potentially applies to every human action qua human action. So, just as we need to know something about the domestic cat in order to grasp that what this cat is doing, here and now, so too we need to know how it is that human beings live generally in order to grasp what this human is doing, here and now. Moreover, to talk about 'the human' or 'human life' generally is to deploy the concept of a life form, which sets a normative standard for particulars that fall under it.

In a later paper titled "Good and Bad Human Action" (2005a), Anscombe proposed the following formula: an action is good qua human action if it can be truthfully described as living well, and it is to some degree bad if it cannot. That is to say, action is good if it is no way bad - it is praiseworthy if it is in no respect blameworthy - such that 'swatting away a fly' might be truthfully described as 'living well' in certain circumstances, just as much as 'enjoying a glass of wine', 'saving a drowning child', 'paying a debt', or 'keeping one's promise.' 
If we allow for this formal measure of 'living well' into our account of intentional action in the way I have been suggesting in this paper, then we can articulate the connection between action theory and ethics as follows. Action theory aims to give an account of practical reason and will in exercise, ${ }^{44}$ whereas ethics aims to give an account of these powers in their perfected condition, as exemplified in the practically wise. The transition from action theory to ethics, then, is the transition from thought about capacities in exercise to thought about the dispositions necessary to perfect their operations towards a single, unifying end: living well for the human person. Since only the practically wise judge truly about the good human life, and since only those with moral virtue stably want the goods that constitute it, ethical reflection will involve, among other things, an understanding of these dispositions and the goods they can secure for us.

In my view this suggestion fits with Anscombe's own narrowly prescribed account of practical reasoning in Intention. For after posing the question what the syllogism has to do with ethics, Anscombe suggests:

It can only come into ethical studies if a correct philosophical psychology is requisite for a philosophical system of ethics. I am not saying that there cannot be any such thing as moral general premises, such as 'People have a duty of paying their employees promptly' ... obviously there can, but it is clear that such general premises will only occur as premises of practical reasoning in people who want to do their duty. The point is very obvious but has been obscured by the conception of the practical syllogism as of its nature ethical, and thus as a proof about what one ought to do, which somehow naturally culminates in action (2000: 78).

We are now in a position to understand why the syllogism must not be understood as an ethical proof. The role of the syllogism is to display a logical form of reasoning that is common to the wicked and the virtuous alike. Whether what is stated in the first premise picks out an end one ought truly to pursue is a question that goes beyond the action theoretic analysis of Intention. What we can know from analyzing action-even the actions of deplorable Nazis - is that there is a rational order internal to human actions that can be understood in terms of the agent's practical reasons.

If the syllogism is not essentially ethical, and if Intention does not provide an account of right practical reasoning, then how does action theory provide the nec-

44. Anscombe herself freely adopts the faculty psychology terminology of capacity and exercise in order to argue that practical knowledge is the capacity of human agency, of having practical knowledge of what one does. She writes, "if we hear of a capacity, it is reasonable to ask what constitutes an exercise of it. In the case of practical knowledge, the exercise of the capacity is nothing but the doing or supervising of the operations of which a man has practical knowledge" (2000: 88). 
essary foundation for ethics? On my reading of Anscombe, what action theory provides is a theory of intentional descriptions as objects of practical knowledge, which is knowledge of what, why, and how what one does is in service of some intended good one has decided to pursue. Such a view shows the essential connection between practical reason, will, and action, and elucidates the capacity to know what one is doing, all the way up to the description of 'living well.' This capacity of practical knowledge is exercised anytime one acts intentionally, and it is this capacity that is perfected in the person who is practically wise-the one who is truly disposed to live well. On Anscombe's account, the fact that the actions of the practical wise are moral would not be something added to the characterization of her more basic intentional descriptions; rather, their moral character is always implicitly contained in the very idea of an intentional description as a certain form of description of events. 45 It follows that Anscombe's theory of intentional descriptions allows us to make sense of the claim that human action is moral action; that is, that each particular human action is, qua action, capable of either truly or falsely being described as 'living well' - as hitting the intrinsic aim of right practical reasoning or not hitting it. In this sense, it can serve as the proper foundation for an ethics that takes 'living well' as its central concept. ${ }^{46}$ And we may be inclined to think that Anscombe was correct to argue that we must do action theory first, since it would have been difficult to arrive at this formulation had we not agreed to follow Anscombe's advice in "Modern Moral Philosophy", which was to " banish ethics totally from our minds" and put talk of the moral 'ought' on the index (2005b: 188). The difficulty arises because talk of 'moral' in the modern sense prevents us from hearing it in the proper register: as 'living well.'

\section{Acknowledgements}

I have been working on this paper for some time. I presented earlier versions of this paper at Florida State, Northwestern, Oxford, Tulane, University of Chicago, Universität Leipzig, University of Notre Dame, University of Pittsburgh, and the University of Tennessee, and I am grateful to those audiences for helpful feedback. I am also grateful to the two anonymous referees for this journal whose insightful commentary greatly improved the final version. Finally, I am grateful to the following for the institutional support for this research: The John Templeton Foundation (grant ID 56194), The Office of the Provost's Internal Grant Program

45. Anscombe explicitly endorses this view in (2005a) and does not note that this is a dramatic change from her earlier views.

46. That we should pursue such an ethics was one of the central suggestions of "Modern Moral Philosophy." 
at the University of South Carolina, and to the Alexander von Humboldt Professorship of James Conant.

\section{References}

Anscombe, Elizabeth (1981a). Mr. Truman's Degree. In The Collected Philosophical Papers Volume III, Ethics, Religion, and Politics (62-71). Blackwell.

Anscombe, Elizabeth (1981b). On Promising and Its Justice, and Whether It Needs Be Respected In Foro Interno. In The Collected Philosophical Papers Volume III, Ethics, Religion, and Politics (10-21). Blackwell.

Anscombe, Elizabeth (1981c). The Intentionality of Sensation: A Grammatical Feature. In The Collected Philosophical Papers, Volume II: Metaphysics and the Philosophy of Mind (3-20). Blackwell.

Anscombe, Elizabeth (1981d). Thought and Action in Aristotle: What is Practical Truth? In Collected Philosophical Papers Volume I: From Parmenides to Wittgenstein (6677). Blackwell.

Anscombe, Elizabeth (2000). Intention. Harvard University Press.

Anscombe, Elizabeth (2005a). Good and Bad Human Action. In Mary Geach and Luke Gormally (Eds.), Human Life, Action, and Ethics: Essays by G.E.M. Anscombe (195206). Imprint Academic.

Anscombe, Elizabeth (2005b). Modern Moral Philosophy. In Mary Geach and Luke Gormally (Eds.), Human Life, Action, and Ethics: Essays by G.E.M. Anscombe (169-194). Imprint Academic.

Anscombe, Elizabeth (2005c). Practical Inference. In Mary Geach and Luke Gormally (Eds.), Human Life, Action, and Ethics: Essays by G.E.M. Anscombe (109-147). Imprint Academic.

Anscombe, Elizabeth (2005d). Practical Truth. In Mary Geach and Luke Gormally (Eds.), Human Life, Action, and Ethics: Essays by G.E.M. Anscombe, (149-158). Imprint Academic.

Aquinas, Thomas (1882). Summa Theologiae. Leonine Edition.

Aristotle (1984). The Complete Works. J. Barnes (Ed.). Princeton University Press.

Boyle, Matthew, and Douglas Lavin (2010). Goodness and Desire. In Sergio Tenenbaum (Ed.) Desire, Practical Reason, and the Good (161-201). Oxford University Press. https://doi.org/10.1093/acprof:oso/9780195382440.003.0008

Campbell, Lucy (2018). Two Notions of Intentional Action? Solving a Puzzle in Anscombe's Intention. British Journal for the History of Philosophy, 26(3), 578-602. https://doi.org/10.1080/09608788.2017.1396959

Davidson, Donald (1980a). Actions, Reasons, and Causes. In Essays on Actions and Events (3-20). Clarendon. https://doi.org/10.1093/0199246270.003.0001

Davidson, Donald (1980b). Agency. In Essays on Actions and Events (43-62). Clarendon. https://doi.org/10.1093/0199246270.003.0003

Davidson, Donald (1980c). How Is Weakness of the Will Possible? In Essays on Actions and Events (21-42). Clarendon. https://doi.org/10.1093/0199246270.003.0002

Davidson, Donald (1980d). Intending. In Essays on Actions and Events (83-102). Clarendon. https://doi.org/10.1093/0199246270.003.0005

Donnellan, Keith S. (1963). Knowing What I Am Doing. Journal of Philosophy, 6o(14), 401-409. https://doi.org/10.2307/2022825 
Fernandez, Patricio (2016). Practical Reasoning: Where the Action Is. Ethics, 126(4), 86990o. https://doi.org/10.1086/685998

Fine, Kit (1994). Essence and Modality. Philosophical Perspectives, 8, 1-16. https://doi. org/10.2307/2214160

Foot, Philippa (2000). Natural Goodness. Oxford. https://doi.org/10.1093/0198235089 .001 .0001

Ford, Anton (2015). The Arithmetic of Intention. American Philosophical Quarterly 52(2), 129-143.

Ford, Anton (2016). On What Is in Front of Your Nose. Philosophical Topics, 44(1), 141161. https://doi.org/10.5840/philtopics20164419

Frankfurt, Harry G. (1978). The Problem of Action. American Philosophical Quarterly, 15(2), 157-162.

Frey, Christopher (2007). Organic Unity and the Matter of Man. In David Sedley (Ed.), Oxford Studies in Ancient Philosophy (Vol. 32, 167-204). Clarendon Press.

Frey, Christopher and Frey, Jennifer A. (2017). G.E.M. Anscombe on the Analogical Unity of Intention in Perception and Action. Analytic Philosophy, 58(3), 202-247. https:// doi.org/10.1111/phib.12101

Frost, Kim (2014). On the Very Idea of Direction of Fit. Philosophical Review, 123(4), 429484. https://doi.org/10.1215/00318108-2749720

Gibbons, John (2001). Knowledge in Action. Philosophy and Phenomenological Research, 62(3), 579-6oo. https://doi.org/10.1111/j.1933-1592.2001.tb00075.x

Gibbons, John (2010). Seeing What You're Doing. In Tamar Szabo Gendler and John Hawthorne (Eds.), Oxford Studies in Epistemology (Vol. 10, 63-85). Oxford University Press.

Haase, Matthias (2018). Knowing What I Have Done. Manuscrito, 41(4), 195-253. https:// doi.org/10.1590/0100-6045.2018.v41n4.mh

Haddock, Adrian (2011). The Knowledge That a Man has of his Intentional Actions. In Anton Ford, Jennifer Hornsby, and Frederick Stoutland (Eds.), Essays on Anscombe's Intention (147-169). Harvard University Press. https://doi.org/10.4159/harvard.9780674060913.c6

Hursthouse, Rosalind (2000). Intention. In Roger Teichmann (Ed.) Logic, Cause \& Action: Essays in Honour of Elizabeth Anscombe (83-106). Cambridge University Press.

Korsgaard, Christine M. (2009). Self-Constitution: Agency, Identity, and Integrity. Oxford University Press. https://doi.org/10.1093/acprof:oso/9780199552795.003.0001

Lavin, Douglas (2013). Must There Be Basic Action? Noûs, 47(2), 273-301. https://doi. org/10.1111/j.1468-0068.2012.00876.x

Marcus, Eric (2012). Rational Causation. Harvard University Press. https://doi. org/10.4159/harvard.9780674065338

Moran, Richard (2004). Anscombe on 'Practical Knowledge'. In John Hyman and Helen Steward (Eds.) Royal Institute of Philosophy Supplement (43-68). Cambridge University Press. https://doi.org/10.1017/S1358246100008638

Müller, Anselm Winfried (1979). How Theoretical Is Practical Reason. In Cora Diamond and Jenny Teichmann (Eds.), Intention and Intentionality: Essays in Honour of G.E.M. Anscombe (91-108). Cornell University Press.

Paul, Sarah K. (2009). How We Know What We're Doing. Philosophers' Imprint, 9(11), $1-24$.

Rödl, Sebastian (2007). Self-Consciousness. Harvard University Press.

Rödl, Sebastian (2011). Forms of Practical Knowledge and their Unity. In Anton Ford, Jen- 
nifer Hornsby, and Frederick Stoutland (Eds.), Essays on Anscombe's Intention (211241). Harvard University Press. https://doi.org/10.4159/harvard.9780674060913.c9

Rödl, Sebastian (2012). Categories of the Temporal: An Inquiry Into the Forms of the Finite Understanding. Harvard University Press.

Schwenkler, John (2015). Understanding 'Practical Knowledge. Philosophers' Imprint, 15(15), 1-32.

Setiya, Kieran (2007). Reasons Without Rationalism. Princeton University Press.

Setiya, Kieran (2008). Practical Knowledge. Ethics, 118(3), 388-409. https://doi. org/10.1086/528781

Setiya, Kieran (2017). Anscombe on Practical Knowledge. In Practical Knowledge: Selected Essays. Oxford University Press. https://doi.org/10.1093/acprof:o so/9780190462925.001.0001

Small, Will (2012). Practical Knowledge and the Structure of Action. In Abel Günter and James Conant (Eds.) Rethinking Epistemology. Berlin Series in Knowledge Research (Vol. 2, 133-228). De Gruyter. https://doi.org/10.1515/9783110277944.133

Smith, Michael (1987). The Humean Theory of Motivation. Mind, 96(381), 36-61. https:// doi.org/10.1093/mind/XCVI.381.36

Stocker, Michael (1979). Desiring the Bad: An Essay in Moral Psychology. Journal of Philosophy, 76(12), 738-753. https://doi.org/10.2307/2025856

Tenenbaum, Sergio (2007a). Appearances of the Good: An Essay on the Nature of Practical Reason. Cambridge University Press. https://doi.org/10.1017/CBO9780511498855

Tenenbaum, Sergio (2007b). The Conclusion of Practical Reason. In Sergio Tenenbaum (Ed.) New Trends in Philosophy: Moral Psychology (323-343). Rodopi. https://doi. org/10.1163/9789401204576_014

Thompson, Michael (2008). Life and Action: Elementary Structures of Practice and Practical Thought. Harvard University Press. https://doi.org/10.4159/9780674033962

Thompson, Michael (2011). Anscombe's Intention and Practical Knowledge. In Anton Ford, Jennifer Hornsby, and Frederick Stoutland (Eds.), Essays on Anscombe's Intention (198-210). Harvard University Press. https://doi.org/10.4159/harvard.9780674060913.c8

Torralba, José María (2016). On Morally Neutral Actions and the Relevance of Practical Truth for Action Theory. In Luke Gormally, David Albert Jones, and Roger Teichmann (Eds.), The Moral Philosophy of Elizabeth Anscombe (51-74). Imprint Academic.

Velleman, David J. (1989). Practical Reflection. Princeton University Press.

Velleman, David J. (1992). The Guise of the Good. Noûs, 26(1), 3-26. https://doi. org/10.2307/2215684

Vogler, Candace (2001). Anscombe on Practical Inference. In Elijah Millgram (Ed.) Varieties of Practical Reasoning (437-464). MIT Press.

Vogler, Candace (2002). Reasonably Vicious. Harvard University Press.

Watson, Gary (1975). Free Agency. Journal of Philosophy, 72(8), 205-220. https://doi. org/10.2307/2024703

Wiland, Eric (2013). In the Beginning Was the Doing: The Premises of the Practical Syllogism. Canadian Journal of Philosophy, 43(3), 303-321. https://doi.org/10.1080/004 55091.2013.857139

Wiseman, Rachael (2016). Routledge Philosophy Guidebook to Anscombe's Intention. Routledge. 
